\title{
Time trends in depression prevalence and health-related correlates: results from population-based surveys in Germany $1997-1999$ vs. $2009-2012$
}

\author{
Julia Bretschneider ${ }^{1 *}$ (D) Silke Janitza ${ }^{1}$, Frank Jacobi ${ }^{2}$, Julia Thom ${ }^{1}$, Ulfert Hapke ${ }^{1}$, Tobias Kurth ${ }^{3}$ and Ulrike E. Maske ${ }^{1}$
}

\begin{abstract}
Background: Although an "epidemic" of depression is frequently claimed, empirical evidence is inconsistent, depending on country, study design and depression assessment. Little is known about changes in depression over time in Germany, although health insurance companies report frequency increases. Here we examined time trends in depression prevalence, severity and health-related correlates in the general population.

Methods: Data were obtained from the mental health module of the "German Health Interview and Examination Survey for Adults" (2009-2012, $n=3265)$ and the mental health supplement of the "German National Health Interview and Examination Survey 1998" (1997-1999, $n=4176)$, excluding respondents older than 65. 12-month major depressive disorder (MDD), severity and symptoms were assessed based on the WHO Composite International Diagnostic Interview. Health-related quality of life (SF-36), self-reported sick days or days with limitations in normal daily life activities were examined, too. Calculations were carried out population-weighted. Additional age-standardized analyses were conducted to account for demographic changes.

Results: Overall, MDD 12-month prevalence remained stable at 7.4\%. Women showed a shifted age distribution with increased prevalence at younger ages, and increasing MDD severity. Time trends in health-related correlates occurred both in participants with and without MDD. Mental health disability increased over time, particularly among men with MDD, reflected by the mental component score of the SF-36 and days with activity limitation due to mental health problems. Demographic changes had a marginal impact on the time trends.

Conclusions: In contrast to the ongoing international debate regarding increased depression rates in western countries, we found no increase in overall MDD prevalence in Germany over a long period. In conclusion, increased depression frequencies in national health insurance data and growing health care costs associated with depression are not attributable to overall prevalence changes at a population level. However, shifted age distribution and increased severity among women may reflect a rising depression risk within this specific subgroup, and changes in health-related correlates indicate a growing mental health care need for depression, particularly among men.
\end{abstract}

Keywords: Major depressive disorder, Depression, Prevalence, Time trends, Health-related quality of life, Disease burden, General population, Germany, Epidemiology, Cross-sectional studies

\footnotetext{
* Correspondence: BretschneiderJ@rki.de

${ }^{1}$ Unit 26 Mental Health, Department of Epidemiology and Health Monitoring,

Robert Koch-Institute, Berlin, Germany

Full list of author information is available at the end of the article
}

(c) The Author(s). 2018 Open Access This article is distributed under the terms of the Creative Commons Attribution 4.0 International License (http://creativecommons.org/licenses/by/4.0/), which permits unrestricted use, distribution, and reproduction in any medium, provided you give appropriate credit to the original author(s) and the source, provide a link to the Creative Commons license, and indicate if changes were made. The Creative Commons Public Domain Dedication waiver (http://creativecommons.org/publicdomain/zero/1.0/) applies to the data made available in this article, unless otherwise stated. 


\section{Background}

An "epidemic" of depression as a disease of modernity has been frequently claimed [1-3]. Given the high prevalence and enormous personal and economic disease burden, this discourse highlights a global core health challenge of the 21st century [4-6].

According to the World Health Organization (WHO), over 300 million people were estimated to be affected by depression globally in 2015, an increase of $18.4 \%$ since 2005 [7]. However, changes were mainly attributable to the overall growth of the global population and its changing age structure $[7,8]$. Likewise, a meta-analysis of 116 epidemiological studies revealed no change in the prevalence of major depressive disorder (MDD) between 1990 and 2010 using age-adjusted estimates, challenging the notion of an epidemic [3]. However, the empirical evidence is inconsistent, depending on country, study design, disorder definition and assessment of depression, and several previous studies also indicate a slight increase of depressive symptoms over time [9-12]. The evaluation of time trends based on direct comparisons of population-based data is difficult, and different depression measures lead to varying results [1]. Even if assessed with a fully-structured clinical diagnostic interview based on diagnostic criteria of the Diagnostic and Statistical Manual of Mental Disorders (DSM), the "gold standard" for estimating depression prevalence [13, 14], prevalence estimates are affected by minor changes in the diagnostic criteria and revisions of clinical interviews or diagnostic algorithms used in mental health survey replications [15]. Thus, there is little agreement about whether depression prevalence is increasing over time or not. However, there is no evidence for a reduction in prevalence $[16,17]$.

In Germany, little is currently known about changes in depression prevalence over time. However, health insurance companies have reported an increasing depression frequency [18], and health care costs attributable to depression have increased considerably [19]. Besides the possibility of increasing depression prevalence in the general population, time trends in health insurance data could also reflect a rising need for mental health care (e.g., due to increasing functional disability). Therefore, the current study sought to examine changes over a period of 13 years for MDD prevalence, severity, symptoms, and health-related correlates for the general population in Germany.

\section{Methods}

\section{Study design and population}

Mental disorders, including MDD, were assessed in the mental health module of the first wave of the "German Health Interview and Examination Survey for Adults" (DEGS1-MH, data collection 2009-2012, age range 18-
79 years) and the mental health supplement of its predecessor, the "German National Health Interview and Examination Survey 1998" (GHS-MHS, data collection 1997-1999, age range 18-65 years). Both surveys were part of the German health monitoring system at the Robert Koch-Institute. They provide representative nationwide data about the health of the non-institutionalized adult population in Germany. Design and methods are described in detail elsewhere [20-24]. In brief, the core surveys GHS and DEGS1 were conducted using two-stage clustered random sampling (step 1: random selection of study locations from all municipal communities; step 2: random selection of participants from population-registries in each selected study location). The net samples of GHS $(n=7124$, response rate: $61 \%)$ and DEGS1 $(n=7115$, including 3959 participants who participated in both surveys, response rates: $64 \%$ among former GHS participants and $42 \%$ for newly sampled individuals) enable representative cross-sectional and trend analyses [25]. The mental health assessment was completed by $n=4181$ participants in GHS (conditional response rate: $87.6 \%$, see [23]) and $n=4483$ participants in DEGS1 (conditional response rate: $88.2 \%$, see [24]). Excluding participants with missing data regarding 12-month MDD from both surveys and participants older than 65 from DEGS1-MH, the final study sample was $n=4176$ for GHS-MHS and $n=3265$ for DEGS1-MH.

\section{Assessment of depression}

Major depressive disorder (MDD) during the last 12 months was assessed by trained interviewers based on the WHO Composite International Diagnostic Interview (CIDI). The CIDI is a standardized fully-structured computer-assisted clinical face-to-face interview. It is widely used internationally in the assessment of mental disorders according to the diagnostic criteria of the DSM [13, 26, 27]. A modified German version of the CIDI, the Munich Composite International Diagnostic Interview, was used in the GHS-MHS (DIA-X/M-CIDI; [28]) and modified for DEGS1-MH (DEGS-CIDI; [24]) to assess mental disorders, according to the diagnostic criteria of the DSM-IV and DSM-IV-TR, respectively [29]. MDD requires the persistence of at least five of nine depression symptoms on nearly every day for 2 weeks or longer, of which at least one is depressed mood or decreased interest/pleasure (DSM criterion A). Furthermore, clinically significant distress and impairment associated with these symptoms are necessary (DSM criterion C). MDD exclusion criteria include lifetime manic/hypomanic episodes and depressive symptoms solely attributable to the direct physiological effects of a substance, a general medical condition or attributable to grief. The questions related to depression assessment were similar in the versions of the CIDI in both the 
GHS-MHS and DEGS1-MH. However, skip rules, and diagnostic algorithms for deduction of 12-month MDD diagnosis differed slightly. Therefore, trend analyses were based on a specific unified diagnostic algorithm. In brief, the algorithm for 12-month MDD was limited to information about the last 12 months without considering lifetime information on symptoms and disorders, and the operationalization of exclusion criteria was harmonized between DEGS1-MH and GHS-MHS. This modified algorithm enables the estimation of prevalence changes over time but also leads to slightly different estimates compared with previously published MDD prevalence data for Germany [30-32]. For participants with 12-month MDD, depression severity was categorized based on the number of depression symptoms into "mild" (5 symptoms), "moderate" (6-7 symptoms) and "severe" (8-9 symptoms) (see [33]).

\section{Other measures}

In the core surveys (GHS and DEGS1), socio-demographic variables were assessed, including sex, marital status (married and living with partner, married and not living with partner, single, divorced, widowed), socio-economic status (SES; classified in low, middle and high based on information on education, occupational, status and net household income, see [34]) and community size [categorized in rural $(<5000$ inhabitants), small town $(5000$ to $<20,000)$, mid-sized town $(20,000$ to $<100,000)$ and large town, see [25]. Age was assessed in years at the time of mental health assessment (GHS-MHS and DEGS1-MH) and categorized into age groups (18-34, 35-49 and 50-65).

Self-rated health and health-related quality of life (past 4 weeks) were assessed with a self-administered questionnaire using the German version of the Short Form 36 (SF-36) version 1 in the GHS $[35,36]$ and version 2 in the DEGS1 [37, 38]. The first question in the SF-36 (identical in both versions) measuring self-rated health was dichotomized into poor/fair vs. good/very good/excellent (see [39]). The SF-36 distinguishes eight domains for health-related quality of life: physical functioning, role physical, bodily pain, general health, vitality, social functioning, role emotional and mental health. A physical component score (PCS) and a mental component score (MCS) are constructed as total scales. "Norm-based scoring" enabled comparability between SF-36 versions (see [37]). Thus, SF-36 scales of both versions were standardized to the 1998 American normative random sample then transformed to an average value of 50 and a standard deviation of 10. Higher values indicate better health-related quality of life.

The number of days with limitations in normal daily life activities due to mental or physical health problems (past 4 weeks) were assessed in the same way in both survey mental health modules [23, 24]: participants were asked on how many days during the past 4 weeks they were totally limited in daily life activities due to mental and physical health problems. In this study, answers were dichotomized into "no" vs. "any" days with limitation. The number of sick days (past 12 months) was assessed in an identical way in both survey mental health modules using a self-administered questionnaire [21, 40] and dichotomized into "no" vs. "any" sick days for this study.

\section{Statistical analysis}

All statistical analyses were performed using survey-specific weighting factors adjusting the study samples to the demographic-geographic distribution of the population in Germany, as on 12/31/1997 (for GHS-MHS) and 12/31/ 2010 (for DEGS-MH). Adjustment took sex, age, educational status, federal state, and nationality into account, as well as the probability of re-participation in the mental health module subsequent to the core survey [23-25]. Statistical analyses were performed using Stata 14.1 and survey design procedures accounting for clustering and weighting. Statistical significance was based on a two-sided significance level of 0.05 . Analyses were not adjusted for multiple testing. Prevalence, frequencies, means and 95\% confidence intervals $(95 \%-\mathrm{CI})$ for all measures were reported for each sex for participants aged 18-65 years in the GHS-MHS and DEGS1-MH. In addition, estimates from age-standardized analyses were reported where appropriate. Note that the provided age-standardized values cannot be interpreted as valid cross-sectional population estimates themselves, but reflect changes over time that are unaffected by demographic changes in the underlying population. To calculate age-standardized prevalence estimates, participants from the GHS-MHS were weighted to the demographic-geographic population structure underlying the DEGS1-MH (as on 12/31/2010).

Distribution of depression severity and prevalence of depression symptoms were reported for cases with 12-month MDD. The Rao-Scott chi-square test was used to test time trends. Age-adjusted results are described for depression severity based on multinomial logistic regression model with depression severity as dependent variable including time point (GHS-MHS vs. DEGS1-MH) and age as independent variables (reference: 1997-1999). Health-related correlates are reported for participants with and without 12-month MDD to enable evaluation of time trends for MDD cases compared with the remaining population. The number of sick days was examined if participants reported any sick days. Effect estimates for time trends were calculated based on linear, logistic and negative binomial regression models, including MDD, time point (GHS-MHS vs. DEGS1-MH) and the interaction between MDD and time point as independent variables (reference: 1997-1999). 
Results of additional age-adjusted regression models are supplementary and described only if divergent from unadjusted results.

\section{Results}

Demographic features of GHS-MHS and DEGS1-MH are shown in Table 1. Overall, the sample characteristics showed little change in the underlying population between 1997-1999 and 2009-2012 regarding the included variables, except for age distribution (shift towards older age) and marital status (being married and living with a partner became less frequent, while the proportion of singles increased).

\section{2-month prevalence of MDD}

Overall 12-month MDD prevalence was stable over time (GHS-MHS: 7.4\%, 95\%-CI: 6.5-8.5 vs. DEGS1-MH: 7.4\%, 95\%-CI: 6.1-8.8; $p=0.93$ when testing for differences), as well as age-standardized prevalence (GHS-MHS: 7.4\%, 95\%-CI: $6.4-8.6$ vs. DEGS1-MH: 7.4\%, 95\%-CI: 6.1-8.8; $p=0.96)$. Although prevalence estimates slightly increased in women and decreased in men, these changes were not statistically significant (see Fig. 1). This was also the case with age-standardization (women: GHS-MHS: 9.6\%, 95\%-CI: $8.0-11.5$ vs. DEGS1-MH: $10.5 \%$, 95\%-CI: $8.6-$ 12.8; $p=0.53$; men: GHS-MHS: 5.2\%, 95\%-CI: 4.1-6.5 vs. DEGS1-MH: $4.2 \%, \quad 95 \%-\mathrm{CI}: \quad 3.3-5.4 ; \quad p=0.22$ ). There were no significant sex differences regarding prevalence trends (logistic model with MDD as dependent variable, $p=0.30$ for testing the interaction between sex and time point, resp. 0.13 with age-standardization). Prevalence among women was significantly higher than among men at both time points.

There were significant age-specific time trends for women (see Table 2): 12-month prevalence of MDD increased in women aged 18 to 34 years $(p=0.005)$ from $8.8 \%$ (95\%-CI: $6.6-11.6)$ to $15.6 \%$ (95\%-CI: $11.3-21.0)$ and decreased in the oldest age group $(p=0.002)$ from $9.8 \%$ (95\%-CI: 7.3-13.0) to 5.0\% (95\%-CI: 3.5-7.1). In contrast, for women aged 35 to 49 years the prevalence remained constant, at approximately $11 \%$. For men, prevalence estimates did not significantly differ within age groups. There were also no significant changes over time depending on socioeconomic status for men and women.

Table 1 Sample characteristics of GHS-MHS (1997-1999) ${ }^{1}$ and DEGS1-MH (2009-2012)

\begin{tabular}{|c|c|c|c|c|}
\hline & \multicolumn{2}{|l|}{ Men } & \multicolumn{2}{|l|}{ Women } \\
\hline & $\begin{array}{l}\text { GHS-MHS } \\
(n=1911)\end{array}$ & $\begin{array}{l}\text { DEGS1-MH } \\
(n=1522)\end{array}$ & $\begin{array}{l}\text { GHS-MHS } \\
(n=2265)\end{array}$ & $\begin{array}{l}\text { DEGS1-MH } \\
(n=1743)\end{array}$ \\
\hline \multicolumn{5}{|l|}{ Age group (years), \% (95\%-Cl) } \\
\hline $18-34$ & $36.4(33.5-39.5)$ & $30.0(26.9-33.2)$ & $35.4(33.0-37.9)$ & $31.3(28.8-34.0)$ \\
\hline $35-49$ & $34.0(31.4-36.7)$ & $36.0(33.1-39.0)$ & $33.3(31.0-35.8)$ & $36.1(33.4-39.0)$ \\
\hline $50-65$ & $29.6(27.0-32.3)$ & $34.0(31.3-36.9)$ & $31.3(29.3-33.4)$ & $32.5(30.0-35.2)$ \\
\hline \multicolumn{5}{|l|}{ Socioeconomic status 3 , \% (95\%-Cl) } \\
\hline Low & $17.0(14.7-19.6)$ & $18.2(15.4-21.3)$ & $17.6(15.4-20.1)$ & $16.9(14.5-19.6)$ \\
\hline Medium & $61.4(58.8-63.9)$ & $58.3(54.9-61.6)$ & $62.9(60.4-65.4)$ & $63.1(59.5-66.6)$ \\
\hline High & $21.7(19.1-24.5)$ & $23.5(20.8-26.5)$ & $19.4(17.2-21.9)$ & $20.0(17.6-22.6)$ \\
\hline \multicolumn{5}{|l|}{ Community size 4 , \% (95\%-Cl) } \\
\hline Rural (<5000 inhabitants) & $20.8(14.0-29.8)$ & $15.9(10.6-23.2)$ & $18.9(12.6-27.4)$ & $14.5(9.4-21.5)$ \\
\hline Small town $(5000$ to $<20,000)$ & $21.9(14.7-31.5)$ & $23.8(17.4-31.7)$ & $19.9(13.3-28.5)$ & $24.0(17.6-31.8)$ \\
\hline Mid-sized town $(20,000$ to $<100,000)$ & $26.7(19.1-36.0)$ & $29.2(22.1-37.6)$ & $28.7(20.7-38.3)$ & $29.8(22.7-37.9)$ \\
\hline Large town $(\geq 100,000)$ & $30.6(22.5-40.1)$ & $31.0(23.8-39.3)$ & $32.6(24.1-42.4)$ & $31.8(24.5-40.1)$ \\
\hline \multicolumn{5}{|l|}{ Marital status, \% (95\%-Cl) } \\
\hline Married and living with partner & $63.3(60.2-66.2)$ & $57.9(54.4-61.2)$ & $65.3(62.2-68.3)$ & $59.2(55.8-62.4)$ \\
\hline Married and not living with partner & $1.9(1.2-3.0)$ & $1.7(1.0-3.0)$ & $2.9(2.1-3.9)$ & $2.5(1.6-3.7)$ \\
\hline Single (never been married) & $28.9(26.3-31.7)$ & $34.3(31.2-37.6)$ & $20.7(18.5-23.0)$ & $28.1(25.3-31.0)$ \\
\hline Divorced & $4.9(3.9-6.3)$ & $5.2(3.9-6.9)$ & $6.7(5.4-8.3)$ & $6.9(5.6-8.6)$ \\
\hline Widowed & $1.0(0.6-1.6)$ & $0.9(0.4-1.9)$ & $4.4(3.4-5.7)$ & $3.4(2.5-4.7)$ \\
\hline
\end{tabular}

${ }^{1}$ German National Health Interview and Examination Survey 1998, mental health supplement (GHS-MHS, 1997-1999): weighted for population structure as of 12/ 31/1997; age range: 18-65; $n=4176$ with full mood disorders section within the Composite International Diagnostic Interview (CIDI)

${ }^{2}$ German Health Interview and Examination Survey for Adults, mental health module (DEGS1-MH, 2009-2012): weighted for population structure as of 12/31/2010; age range: $18-65 ; n=3265$ with full mood disorders section within the Composite International Diagnostic Interview (CIDI)

${ }^{3}$ Based on information regarding education, occupational status and net household income

${ }^{4}$ GHS-MHS: community size as of 12/31/1996; DEGS1-MH: community size as of 12/31/2006 


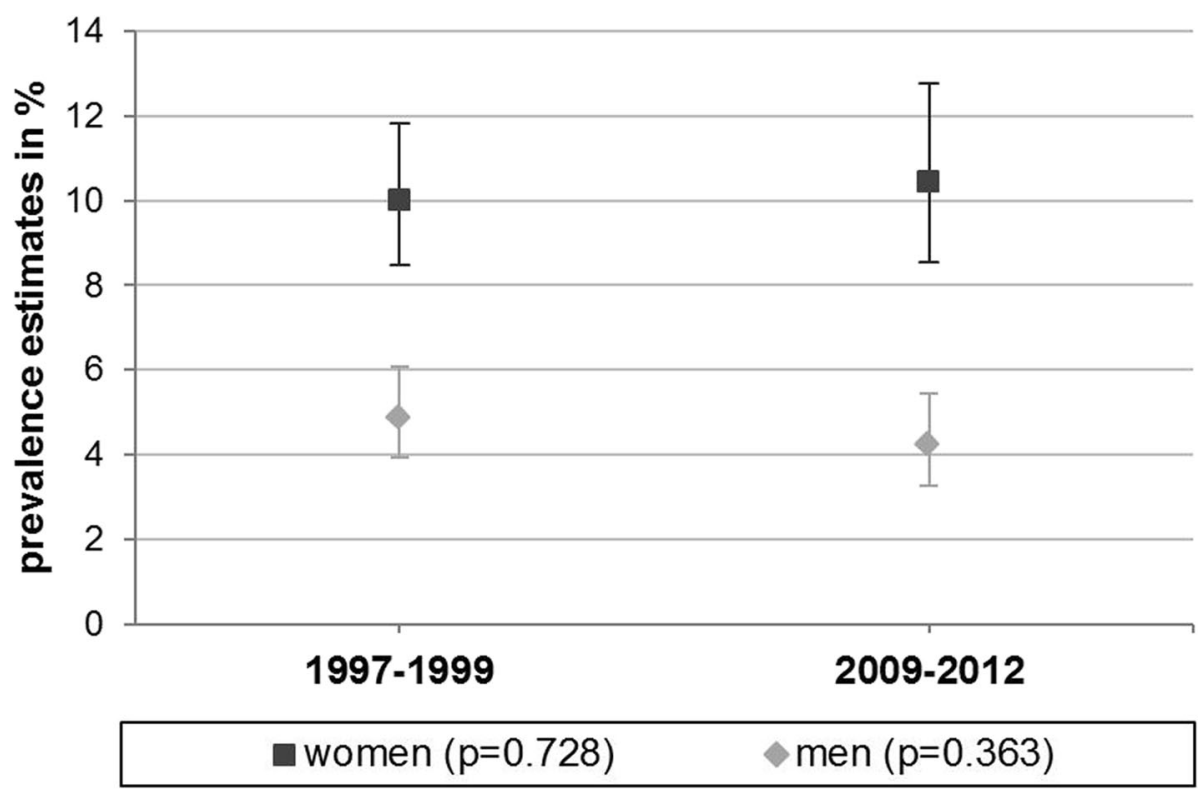

Fig. 1 12-month prevalence of MDD 1997-1999 (GHS-MHS: German National Health Interview and Examination Survey 1998, mental health supplement, weighted for population structure as of 12/31/1997) vs. 2009-2012 (DEGS1-MH: German Health Interview and Examination Survey for Adults, mental health module, weighted for population structure as of 12/31/2010). Age range: 18-65; $p$-values: Rao-Scott chi-square test for testing differences between 1997-1999 and 2009-2012

Further analyses revealed similar significant differences and comparable prevalence estimates within age groups, and, with regard to socioeconomic status, when controlling for sociodemographic variables (logistic models adjusting for socioeconomic status, or age, as well as community size and marital status; results not shown).
Distribution of depression severity and depression symptoms in cases with 12-month MDD

Overall, for men and women with 12-month MDD, moderate severity was most frequent $(>40 \%$ at both time points). There was a slight decrease in mild depression over time, while severe depression increased (see Table 3). However, these changes were statistically significant only

Table 2 12-month prevalence of MDD 1997-1999 vs. 2009-2012² by age group and socioeconomic status

\begin{tabular}{|c|c|c|c|c|c|c|}
\hline & \multicolumn{3}{|l|}{ Men } & \multicolumn{3}{|l|}{ Women } \\
\hline & $\begin{array}{l}1997-1999 \\
(n=1911)\end{array}$ & $\begin{array}{l}2009-2012 \\
(n=1522)\end{array}$ & $p$-value ${ }^{3}$ & $\begin{array}{l}1997-1999 \\
(n=2265)\end{array}$ & $\begin{array}{l}2009-2012 \\
(n=1743)\end{array}$ & $p$-value \\
\hline Total, \% (95\%-Cl) & $4.9(3.9-6.1)$ & $4.2(3.3-5.4)$ & 0.363 & $10.0(8.5-11.8)$ & $10.5(8.6-12.8)$ & 0.728 \\
\hline \multicolumn{7}{|c|}{ Age group (years), \% (95\%-Cl) } \\
\hline $18-34$ & $4.4(3.0-6.5)$ & $4.0(2.4-6.7)$ & 0.761 & $8.8(6.6-11.6)$ & $15.6(11.3-21.0)$ & 0.005 \\
\hline $35-49$ & $5.4(3.9-7.5)$ & $4.0(2.4-6.7)$ & 0.333 & $11.5(9.2-14.3)$ & $11.0(8.1-14.7)$ & 0.787 \\
\hline $50-65$ & $4.9(3.4-6.9)$ & $4.6(3.1-6.8)$ & 0.812 & $9.8(7.3-13.0)$ & $5.0(3.5-7.1)$ & 0.002 \\
\hline \multicolumn{7}{|l|}{ SES, \% (95\%-Cl) } \\
\hline Low & $5.6(2.9-10.5)$ & $5.1(2.7-9.5)$ & 0.864 & $11.7(8.4-16.0)$ & $17.0(11.1-25.2)$ & 0.128 \\
\hline Middle & $5.3(4.1-6.9)$ & $4.4(3.1-6.2)$ & 0.331 & $10.1(8.2-12.3)$ & $9.3(7.1-12.1)$ & 0.610 \\
\hline High & $3.3(2.2-5.0)$ & $3.1(1.7-5.7)$ & 0.874 & $8.6(6.4-11.5)$ & $8.6(5.6-12.7)$ & 0.981 \\
\hline
\end{tabular}

${ }^{1}$ German National Health Interview and Examination Survey 1998, mental health supplement (GHS-MHS, 1997-1999): weighted for population structure as of 12/ 31/1997; age range: $18-65$

${ }^{2}$ German Health Interview and Examination Survey for Adults, mental health module (DEGS1-MH, 2009-2012): weighted for population structure as of 12/31/2010; age range: $18-65$

${ }^{3} p$-value based on Rao-Scott chi-square test. Bold type indicates significant differences between 1997-1999 and 2009-2012 (local significance level $a=0.05$ ) 
Table 3 Depression severity in cases with 12-month MDD 1997-1999 vs. 2009-2012²

\begin{tabular}{|c|c|c|c|c|c|c|}
\hline & \multicolumn{3}{|l|}{ Men } & \multicolumn{3}{|l|}{ Women } \\
\hline & $\begin{array}{l}1997-1999 \\
(n=110)\end{array}$ & $\begin{array}{l}2009-2012 \\
(n=71)\end{array}$ & $p$-value ${ }^{3}$ & $\begin{array}{l}1997-1999 \\
(n=238)\end{array}$ & $\begin{array}{l}2009-2012 \\
(n=159)\end{array}$ & $p$-value \\
\hline \multicolumn{7}{|l|}{ Depression severity, \% (95\%-Cl) } \\
\hline Mild (5/9 symptoms) & $31.7(22.3-42.9)$ & $27.1(16.2-41.7)$ & 0.574 & $24.1(18.3-30.9)$ & $13.8(8.0-22.7)$ & 0.045 \\
\hline Moderate ( $6+7 / 9$ symptoms) & $45.0(35.2-55.1)$ & $43.0(31.0-55.9)$ & 0.803 & $41.5(34.2-49.2)$ & $47.2(37.0-57.7)$ & 0.329 \\
\hline Severe (8 + 9/9 symptoms) & $23.3(15.8-33.1)$ & $29.9(19.0-43.7)$ & 0.373 & $34.5(27.2-42.6)$ & $39.0(28.2-51.1)$ & 0.466 \\
\hline
\end{tabular}

for women with mild depression, decreasing from $24.1 \%$ to $13.8 \%(p=0.045)$. Comparable results were obtained when controlling for age in a multinomial logistic model (results not shown). Furthermore, differences observed were not attributable to changes only within specific age groups (results not shown).

Prevalence of the nine depression symptoms in cases with 12-month MDD was heterogeneous (see Additional file 1). Over time, there was a significant increase in the frequency of reporting a feeling of guilt/worthlessness in men $(p=0.035)$ and women $(p=0.019)$. In addition, women reported significant weight/appetite change more frequently in 2009-2012 $(p<0.001)$ and diminished interest/pleasure less frequently $(p=0.018)$.

\section{Health-related correlates}

Overall, men and women with 12-month MDD exhibited worse outcomes for all health-related correlates than participants without MDD at both time points (see Table 4). Participants with 12-month MDD reported fair/poor self-rated health significantly more often, had significantly lower health-related quality of life in all SF-36 sub-scales, and reported days with activity limitation due to mental health problems and sick days more frequently than participants without MDD.

The proportion of women with 12-month MDD reporting fair/poor self-rated health significantly decreased over time from $40.4 \%$ to $21.3 \%$ (odds ratio [OR] $=0.4, p=0.001$, see Table 5). This decrease was significantly more pronounced among women with 12-month MDD ( $p=0.043)$ compared with the trend in women without MDD $(\mathrm{OR}=0.7)$. However, the trends converged when effect estimates were adjusted for age $(\mathrm{OR}=0.5 \mathrm{vs}$. $\mathrm{OR}=0.7, p=0.39$, see Additional file 2). For men with MDD, there was no significant change in self-rated health over time $(\mathrm{OR}=1.0)$ and no significant divergence $(p=0.37)$ from the trend in men without MDD $(\mathrm{OR}=0.7$ ).

Health-related quality of life (past 4 weeks) changed over time: women with 12-month MDD showed a significant improvement for the physical component by an average of 3.8 points and a small but non-significant deterioration in the mental component (by -1.2 points), when comparing participants between 1997-1999 and 2009-2012. These trends did not significantly differ from female participants without $\operatorname{MDD}(p=0.11$ and $p=0.87$, respectively). For men with 12 -month MDD, there was no significant change over time in the physical component (by -0.8 points), but also no significant divergence $(p=0.25)$ from the improvement observed in men without MDD. In contrast, aggravation of the mental component over time in men with MDD (by -5.2 points) was significantly more pronounced $(p=0.033)$ compared with men without MDD (see Fig. 2). The outlined effect estimates for the total scales were comparable when adjusted for age, except for minor differences (see Additional file 2). The results for the total scales reflect changes regarding the SF-36 sub-scales. Women with 12-month MDD showed significant improvement in bodily pain over time (by 6.1 points). For all sub-scales, time trends did not significantly differ between women with and without MDD. In contrast, men showed a slight aggravation over time on all SF-36 subscales, reaching significance for social role functioning (by -4.4 points) and emotional role functioning (by -8.3 points). These time trends among men with MDD differed significantly from men without MDD in emotional role functioning $(p=0.006)$ and bodily pain $(p=0.030)$.

The risk of experiencing any days with activity limitation (past 4 weeks) due to mental health problems was significantly higher in 2009-2010 compared with 1997-1999 for men and women, whether MDD was present or not (with ORs ranging from 2.3 to 6.5 ). However, there was a trend towards a more pronounced increase in women with MDD compared with women without MDD $(p=0.056)$. In contrast, the risk of experiencing days with activity limitation due to physical health problems did not significantly change over time. The proportion of days with limitations due to physical health problems was already significantly higher in 1997-1999 compared with 


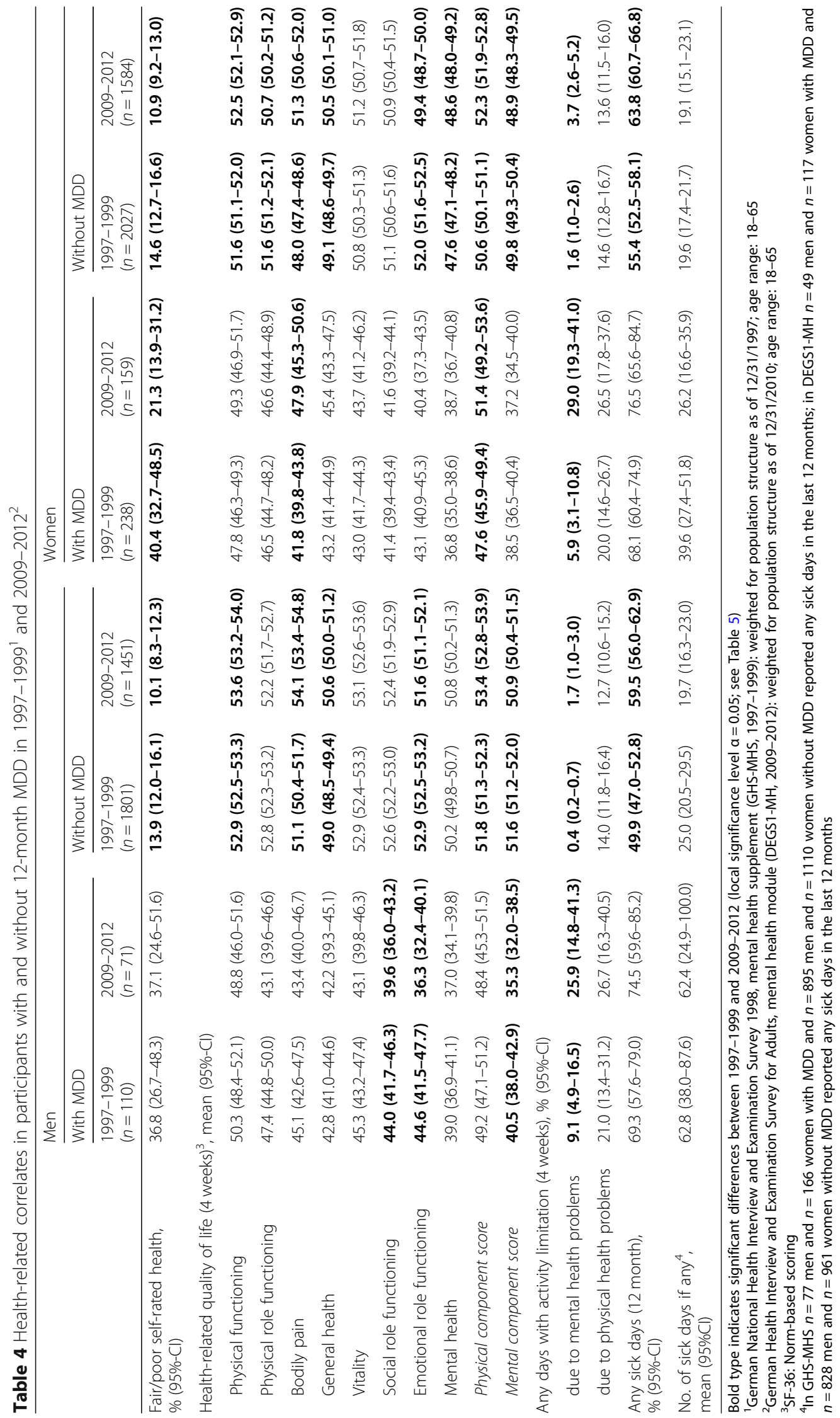




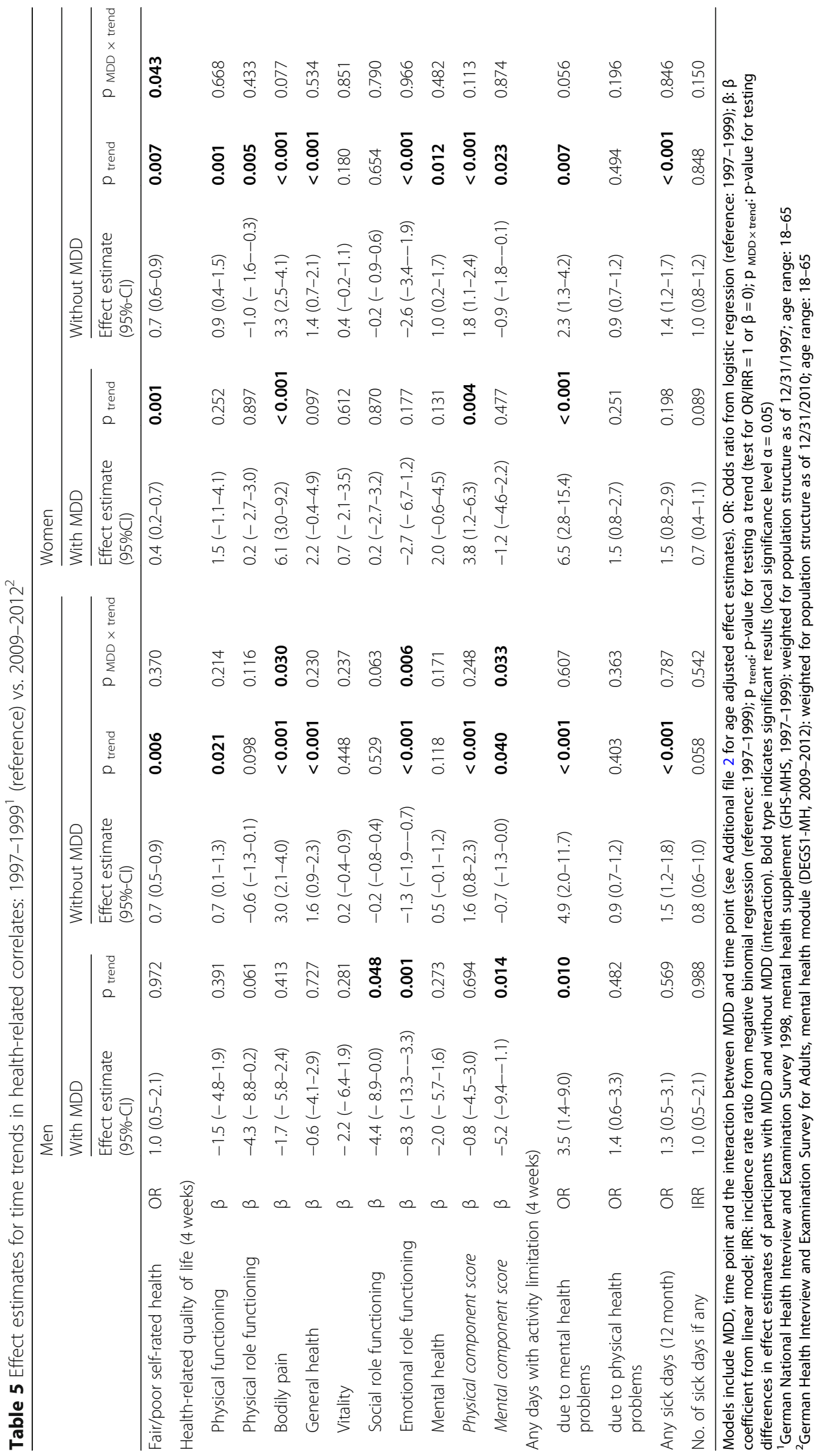




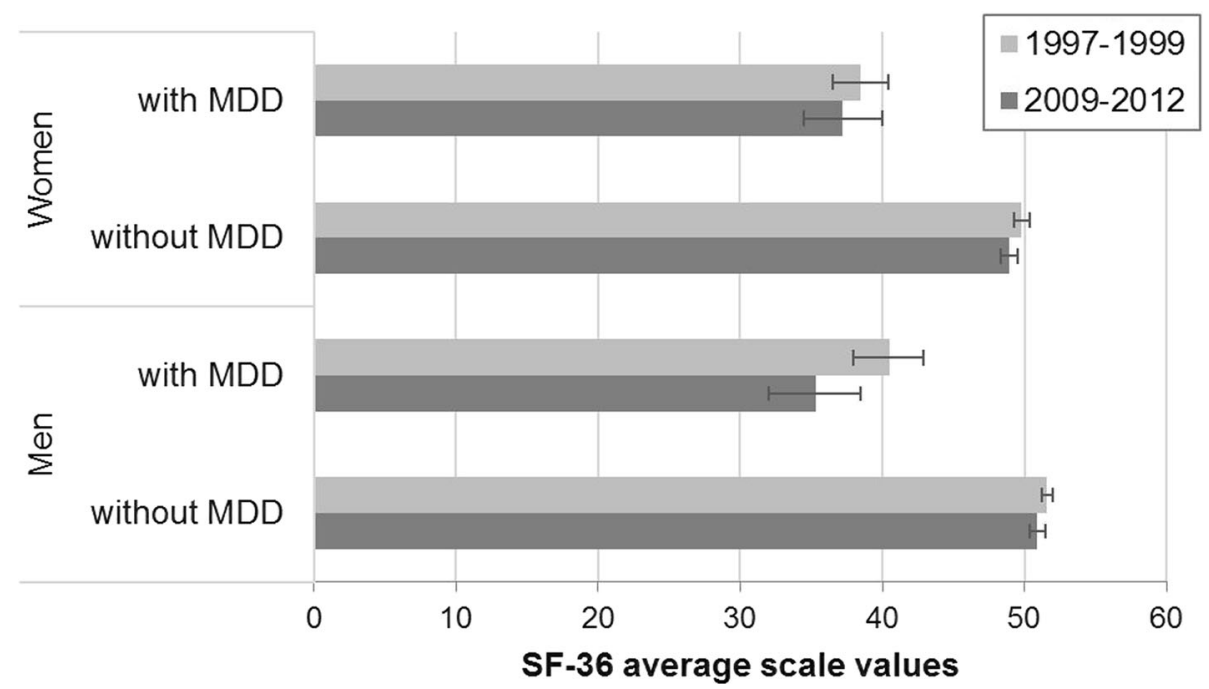

Fig. 2 Health-related quality of life in 1997-1999 (GHS-MHS: German National Health Interview and Examination Survey 1998, mental health supplement, weighted for population structure as of 12/31/1997. Age range: 18-65) vs. 2009-2012 (DEGS1-MH: German Health Interview and Examination Survey for Adults, mental health module, weighted for population structure as of 12/31/2010. Age range: 18-65): Mental Component Score (based on SF-36 and norm-based scoring)

limitation days due to mental health problems. In 20092010, at least $25 \%$ of cases with 12-month MDD reported some days involving limitations due to each type of problem.

The risk of having any sick days (past 12 months) slightly rose over time (with ORs ranging from 1.3-1.5), but these changes were significant only for participants without MDD. In 2009-2010, approximately $75 \%$ of cases with 12-month MDD reported sick days. For women with 12-month MDD reporting any sick days, there was a trend towards a decreased number of sick days over time, from an average of 39.6 days to 26.2 days (incidence rate ratio $0.7, p=0.089$ ), but no change for women without MDD. For men with depression, there was no change over time in the number of sick days, but also no significant divergence $(p=0.54)$ from the decline in men without MDD (incidence ratio 0.8, $p=0.058$, and incidence ratio $0.7, p=0.005$ when adjusted for age, see Additional file 2).

\section{Discussion}

\section{Prevalence stability}

Based on nationally representative samples of the general adult population, this study revealed no increase in overall 12-month MDD prevalence in Germany over a long period, irrespective of whether the data were standardized for demographic changes. Thus, the increased depression frequencies in health insurance data and increasing costs do not appear to reflect an "epidemic of depression" on a population level. Overall, the current results are in line with the initially presented meta-analysis and findings of the Global Burden of
Disease Study, indicating no substantial change in MDD prevalence between 1990 and 2010, or 2005 and 2015, when adjusting for demographic changes $[3,7,8]$. However, women exhibited an MDD prevalence that was twice as high in the youngest age-group and a decrease in mild depression, corresponding to previous findings of increasing depression prevalence or chronicity in (younger) women [41-43].

Overall prevalence stability has previously been discussed as a potential outcome of improved prevention, mental health care and treatment benefits over time, possibly masking rising depression incidence or severity of illness [17, 44]. Meanwhile, exposure to risk factors for mental disorders in the population may have increased (e.g., higher levels of stress due to growing social inequality, isolation, urbanization and modernization in general; [2, 3]). International findings of increased lifetime depression prevalence and chronicity in younger cohorts appear to support this hypothesis $[43,45,46]$. However, societal changes could also result in reductions of depression risks (e.g., improved education). Furthermore, a general decrease in psychological distress or psychosocial stressors $[47,48]$, stable or even decreasing depression incidence [41, 43, 44], unchanged episode duration [44], and stable severity [49] have also been reported. A recent review concluded that there is no support for the first hypothesis of increasing exposure to risk factors in industrialized countries [17]. Likewise, potential changes in sociodemographic correlates were negligible for prevalence estimates in the current study, even within population subgroups (e.g., age groups). However, understanding the extent to which changes 
among women reflect growing exposure to risk factors over time within this specific subgroup requires further investigation.

\section{Rising mental health care need?}

Changes in health-related correlates revealed increased disability over time in the MCS of SF-36, particularly among men with MDD, and an increased risk of experiencing days with activity limitation due to mental health problems. Thus, the current study provides some evidence of an increased need for mental health care for depression over time, particularly among men. Likewise, national health insurance data documents increasing work day loss attributable to depression (e.g. [50]), and treatment-seeking rates for major depression have been reported to be increasing internationally [51]. However, only relatively small changes were observed in the current study, and only slight improvement in non-help-seeking was reported for participants with mental disorders between 1997-1999 and 2009-2012 (62\% vs. 57\%) in Germany [52]. Thus, increasing depression frequency in health insurance data and growing costs cannot be explained solely by an increased need for mental health care in depression.

However, changes in health-related correlates also occurred in participants without MDD, while the perception of general health improved (see [37]). Likewise, international findings also indicate increasing mental health disability [53] and worsening of perceived mental health status $[47,48]$. Thus, declining mental wellbeing may indicate an increasing need for mental health care in general (e.g., due to rising psychosocial demands over time). Another potential explanation is related to time trends in the process of reporting depressive symptoms themselves. The findings of several previous studies indicate that increased mental health literacy in the general population over time [54, 55] is associated with increased (public) awareness, recognition of psychological symptoms, and willingness to disclose $[9,11,48,56]$, as well as elevated help-seeking behavior $[57,58]$. Thus, increased mental health literacy may have led to a more negative evaluation of stressors and perceived mental health over time, associated with rising subjective health care needs. International findings have indicated such a decrease in perceived mental health, while levels of distress were unchanged $[47,48,53]$. Having poor or fair mental health literacy has even been reported to be protective against MDD [9]. Furthermore, several results indicate age- and sex-dependent symptom expression [59-61], and mental health literacy [9]. Thus, even findings of increasing lifetime prevalence in younger cohorts or rising depression prevalence among younger women may be specifically associated with increased reporting of symptoms. However, only minor changes in health-related correlates were observed overall, and little evidence of rising mental health literacy is available in view of the enormous increases in national health insurance data (see [17]).

\section{Limitations}

The following potential limitations should be considered interpreting the findings of the current study. Underestimation of MDD prevalence at both time points may have been caused by "recall bias", selective non-response of less healthy participants and exclusion of institutionalized individuals in both surveys [21, 22, 24]. Thus, people with severe depression may have been particularly underrepresented. In addition, participants' "reporting bias" and varying diagnostic accuracy between population subgroups may have led to prevalence underestimation in older participants and male participants $[62,63]$. Moreover, the inclusion of some longitudinal data could lead to an underestimation of MDD prevalence in 2009-2012, due to a potentially higher rate of re-participation among healthier participants. Moreover, in the statistical analysis the two survey populations were considered to be independent, neglecting potential correlations related to re-participation of some participants in the DEGS1-MH. The particularly small number of men with MDD in the surveys resulted in low statistical power for detecting time trends within this subgroup. A further potential limitation could be related to the time lags between the core surveys and mental health supplements, which may have led to an underestimation of associations between 12-month MDD and health-related correlates. However, associations may also have been overestimated due to a construct overlap of depressive symptoms (e.g., energy loss) with outcome measures such as SF-36 and self-reported disability.

\section{Conclusions}

The current study provides valid, up-to-date information about time trends in depression prevalence, severity and symptoms in the general population in Germany over a long period with a high-quality diagnostic level. To date, national cross-sectional data has been lacking comparability over time due to divergent measures or diagnostic algorithms. Moreover, this is the first study comparing DSM-IV-based major depression prevalence over time while also considering health-related correlates. Furthermore, the current study also provides an evaluation of time trends in view of demographic changes in the underlying population. Thus, the current findings contribute significantly to the ongoing national and international debate regarding the potential increase of depression in western countries.

In contrast to the frequently claimed "epidemic" of depression, we found stable overall prevalence in Germany between 1997-1999 and 2009-2012. Demographic 
changes had a marginal impact on the examined time trends within the considered age range. In conclusion, increased depression frequencies in national health insurance data and associated growing health care costs are not attributable to overall prevalence changes at a population level.

However, shifted age distribution and increased severity among women may reflect a rising depression risk within this specific subgroup. Furthermore, we found some evidence for an increased need for mental health care for depression over time, particularly among men. However, changes in mental wellbeing also occurred in the general population, which may have also contributed to an increase in depression diagnoses in the health care system. Thus, the observed time trends suggest the need for further investigations of potentially rising psychosocial demands in the general population, and specifically increasing depression risks among women, considering age- and sex-specific developments in mental health literacy.

Finally, divergent time trends in primary and secondary data indicate the need for a critical review of mental health care in Germany, rising questions about the effects of simultaneously expanded services and provision of treatment (e.g. [64]). Jorm AF, Patten SB, Brugha TS and Mojtabai R [17] already highlighted the impact of a "treatment gap", "quality gap" and "prevention gap" for the lack of improvement in population prevalence. In Germany, only $34.6 \%$ of participants with 12-month MDD reported any service use due to mental health problems in 20092012 [65]. Locally varying access to mental health care has previously been identified as an important determinant of help-seeking behavior $[66,67]$. In addition, increasing acceptance of mental health care services [55] and rising public knowledge appear to not have resulted in improved social acceptance of people with mental illness over time [54]. Furthermore, targeting of treatment seems to be questionable: concordance of self-reported clinician diagnosed depression and DSM-IV-based MDD diagnosis is remarkably low [33, 62]. False positive depression diagnoses were particularly high in primary care [68], also indicating "over-representation" of depression within the German health care system, concurrent with the persisting treatment gap. Moreover, national health insurance data provides evidence for lacking quality of treatment [69-73]. These findings suggest that public health initiatives in Germany should continue to reduce access barriers to mental health care services, and focus on improving targeting and quality of treatment for depression. Furthermore, primary and secondary data seem to fundamentally lack comparability with regard to their respective depression indicators. Thus, the current findings emphasize the potential benefits of linking secondary data regarding health care utilization and service provision with standardized measures of depression based on primary data.

\section{Additional files}

Additional file 1: Prevalence of depression symptoms in cases with 12month MDD 1997-1999 vs. 2009-2012 (PDF 127 kb)

Additional file 2: Age-adjusted effect estimates for time trends in healthrelated correlates: 1997-1999 (reference) vs. 2009-2012 (PDF 95 kb)

\begin{abstract}
Abbreviations
CIDI: Composite International Diagnostic Interview; DEGS1: German Health Interview and Examination Survey for Adults; DEGS1-MH: Mental health module of DEGS1; DSM-IV: Diagnostic and Statistical Manual of Mental Disorders, 4th edition; DSM-IV-TR: Diagnostic and Statistical Manual of Mental Disorders, 4th edition, Text Revision; GHS: German National Health Interview and Examination Survey 1998; GHS-MHS: Mental health supplement of GHS; MCS: Mental component score; MDD: Major depressive disorder; PCS: Physical component score; SES: Socio-economic status; SF-36: Short Form 36
\end{abstract}

\section{Acknowledgements}

We thank Benjamin Knight, MSc., from Edanz Group (www.edanzediting.com) for editing a draft of this manuscript.

\section{Funding}

This work was supported by the German Ministry of Health (funding No. ZMV1-2516-FSB-703). GHS was supported by the German Federal Ministry of Research, Education and Science (BMBF, grant 01EH970/8) and conducted by the Robert Koch-Institute, Berlin. Reported data on mental disorders were assessed in GHS-MHS, conducted by the Max-Planck-Institute of Psychiatry, Munich. DEGS1 and DEGS1-MH were funded primarily by the German Ministry of Health (Bundesministerium für Gesundheit, BMG, grant numbers for DEGS1-MH: 1368-1124 and 1501-54401). Supplementary funding for DEGS1-MH was provided by the Technische Universität Dresden, and by the Foundation for Mental Health (Stiftung Seelische Gesundheit) inaugurated by the German Association for Psychiatry, Psychotherapy and Psychosomatics (Deutsche Gesellschaft für Psychiatrie und Psychotherapie, Psychosomatik und Nervenheilkunde, DGPPN).

\section{Availability of data and materials}

The data that support the findings of this study are available from the Robert Koch Institute (RKI) but restrictions apply to the availability of these data, which were used under license for the current study, and so are not publicly available. The data set cannot be made publicly available because informed consent from study participants did not cover public deposition of data. However, a minimal data set is archived in the 'Health Monitoring' Research Data Centre at the Robert Koch Institute (RKI) and can be accessed by all interested researchers. On-site access to the data set is possible at the Secure Data Center of the RKI's 'Health Monitoring' Research Data Centre. Requests should be submitted to the 'Health Monitoring' Research Data Centre, Robert Koch Institute, Berlin, Germany (e-mail: fdz@rki.de).

\section{Authors' contributions}

JB and UEM devised the main conceptual ideas. JB, SJ and UEM designed the study and prepared and analyzed the data. TK contributed by mentoring the analysis. JB interpreted the results and wrote the manuscript. UEM, FJ, JT, $\mathrm{UH}$ and TK contributed to the interpretation of results and critically revised the article. All authors read and approved the final manuscript.

\section{Ethics approval and consent to participate}

Both surveys DEGS1-MH and GHS-MHS were conducted following the Federal and State Commissioners for Data Protection guidelines and the ethical principles of the Helsinki Declaration. DEGS1 and DEGS1-MH were approved by local ethics committees (Charité-Universitätsmedizin Berlin: No. EA2/047/08; Technische Universität Dresden: No. EK174062009). All participants provided written informed consent prior to participation. 


\section{Competing interests}

In the past 3 years, TK has received honoraria for providing methodological advice to Lilly, for a presentation on neuroepidemiology from Novartis, from providing a presentation about clinical research methods from Daiichi-Sankyo, and for providing editorial services from the BMJ. TK has provided methodological advice to CoLucid and Amgen, for which the Charité - Universitätsmedizin Berlin has received unrestricted funds. The remaining authors declare that they have no competing interests.

\section{Publisher's Note}

Springer Nature remains neutral with regard to jurisdictional claims in published maps and institutional affiliations.

\section{Author details}

${ }^{1}$ Unit 26 Mental Health, Department of Epidemiology and Health Monitoring, Robert Koch-Institute, Berlin, Germany. ${ }^{2}$ Psychologische Hochschule Berlin, Berlin, Germany. ${ }^{3}$ Institute of Public Health, Charité - Universitätsmedizin Berlin, Berlin, Germany.

\section{Received: 7 September 2018 Accepted: 5 December 2018}

\section{Published online: 20 December 2018}

\section{References}

1. Busfield J. Challenging claims that mental illness has been increasing and mental well-being declining. Soc Sci Med. 2012;75:581-8.

2. Hidaka $\mathrm{BH}$. Depression as a disease of modernity: explanations for increasing prevalence. J Affect Disord. 2012;140:205-14.

3. Baxter AJ, Scott KM, Ferrari AJ, Norman RE, Vos T, Whiteford HA. Challenging the myth of an "epidemic" of common mental disorders: trends in the global prevalence of anxiety and depression between 1990 and 2010. Depress Anxiety. 2014;31:506-16.

4. Hewlett E, Moran V. Making mental health count. The social and economic costs of neglecting mental health care. Paris: OECD Publishing; 2014.

5. Demyttenaere K, Bruffaerts R, Posada-Villa J, Gasquet I, Kovess V, Lepine JP, Angermeyer MC, Bernert S, de Girolamo G, Morosini P, et al. Prevalence, severity, and unmet need for treatment of mental disorders in the World Health Organization world mental health surveys. Jama. 2004;291:2581-90.

6. Wittchen HU, Jacobi F, Rehm J, Gustavsson A, Svensson M, Jonsson B, Olesen J, Allgulander C, Alonso J, Faravelli C, et al. The size and burden of mental disorders and other disorders of the brain in Europe 2010. Eur Neuropsychopharmacol. 2011;21:655-79.

7. Vos T, Allen C, Arora M, Barber RM, Bhutta ZA, Brown A, Carter A, Casey DC, Charlson FJ, Chen AZ, et al. Global, regional, and national incidence, prevalence, and years lived with disability for 310 diseases and injuries, 1990-2015: a systematic analysis for the global burden of disease study 2015. Lancet. 2016;388:1545-602.

8. Ferrari AJ, Charlson FJ, Norman RE, Patten SB, Freedman G, Murray CJ, Vos T, Whiteford HA. Burden of depressive disorders by country, sex, age, and year: findings from the global burden of disease study 2010. PLoS Med. 2013;10: e1001547.

9. Goldney RD, Eckert KA, Hawthorne G, Taylor AW. Changes in the prevalence of major depression in an Australian community sample between 1998 and 2008. Aust N Z J Psychiatry. 2010;44:901-10.

10. Kovess-Masfety V, Briffault X, Sapinho D. Prevalence, risk factors, and use of health care in depression: a survey in a large region of France between 1991 and 2005. Can J Psychiatr. 2009;54:701-9.

11. Andersen I, Thielen K, Bech P, Nygaard E, Diderichsen F. Increasing prevalence of depression from 2000 to 2006. Scand J Public Health. 2011;39:857-63.

12. Spiers N, Brugha TS, Bebbington P, McManus S, Jenkins R, Meltzer H. Age and birth cohort differences in depression in repeated cross-sectional surveys in England: the National Psychiatric Morbidity Surveys, 1993 to 2007. Psychol Med. 2012;42:2047-55

13. Wittchen HU, Lachner G, Wunderlich $U$, Pfister $H$. Test-retest reliability of the computerized DSM-IV version of the Munich-composite international diagnostic interview (M-CIDI). Soc Psychiatry Psychiatr Epidemiol. 1998;33:568-78.

14. Haro JM, Arbabzadeh-Bouchez S, Brugha TS, de Girolamo G, Guyer ME, Jin $R$, Lepine JP, Mazzi F, Reneses B, Vilagut $G$, et al. Concordance of the composite international diagnostic interview version 3.0 (CIDI 3.0) with standardized clinical assessments in the WHO world mental health surveys. Int J Methods Psychiatr Res. 2006;15:167-80.

15. Karlsson L, Marttunen M, Karlsson H, Kaprio J, Hillevi A. Minor change in the diagnostic threshold leads into major alteration in the prevalence estimate of depression. J Affect Disord. 2010;122:96-101.

16. Richter D, Berger K. Are mental disorders increasing? Update of a systematic review on repeated cross-sectional studies. Psychiatr Prax. 2013;40:176-82.

17. Jorm AF, Patten SB, Brugha TS, Mojtabai R. Has increased provision of treatment reduced the prevalence of common mental disorders? Review of the evidence from four countries. World Psychiatry. 2017;16:90-9.

18. Gerste B, Roick C. Prävalenz und Inzidenz sowie Versorgung depressiver Erkrankungen in Deutschland - Eine Analyse auf Basis der in Routinedaten dokumentierten Depressionsdiagnosen. In: Klauber J, Günster C, Gerste B, Robra B-P, Schmacke N, editors. Versorgungs-Report 2013/2014. Stuttgart: Schattauer; 2014. p. 21-54.

19. Statistisches Bundesamt (Destatis): Gesundheit: Krankheitskosten 2015. 2017.

20. Bellach BM, Knopf H, Thefeld W. The German Health Survey. 1997/98. Gesundheitswesen. 1998;60(Suppl 2):S59-68.

21. Scheidt-Nave C, Kamtsiuris P, Gößwald A, Hölling H, Lange M, Busch MA, Dahm S, Dölle R, Ellert U, Fuchs J, et al. German health interview and examination survey for adults (DEGS) - design, objectives and implementation of the first data collection wave. BMC Public Health. 2012;12:730.

22. Gosswald A, Lange M, Kamtsiuris P, Kurth BM. DEGS: German Health Interview and Examination Survey for Adults. A nationwide cross-sectional and longitudinal study within the framework of health monitoring conducted by the Robert Koch Institute. Bundesgesundheitsbl. 2012;55:775-80.

23. Jacobi F, Wittchen HU, Holting C, Sommer S, Lieb R, Hofler M, Pfister H. Estimating the prevalence of mental and somatic disorders in the community: aims and methods of the German National Health Interview and examination survey. Int J Methods Psychiatr Res. 2002;11:1-18.

24. Jacobi F, Mack S, Gerschler A, Scholl L, Hofler M, Siegert J, Burkner A, Preiss S, Spitzer K, Busch M, et al. The design and methods of the mental health module in the German health interview and examination survey for adults (DEGS1-MH). Int J Meth Psychiatr Res. 2013;22:83-99.

25. Kamtsiuris $P$, Lange M, Hoffmann R, Schaffrath Rosario A, Dahm S, Kuhnert $\mathrm{R}$, Kurth BM. The first wave of the German health interview and examination survey for adults (DEGS1): sample design, response, weighting and representativeness. Bundesgesundheitsbl. 2013;56:620-30.

26. Kessler RC, Ustun TB. The World Mental Health (WMH) survey initiative version of the World Health Organization (WHO) composite international diagnostic interview (CIDI). Int J Methods Psychiatr Res. 2004;13:93-121.

27. Wittchen H-U. Reliability and validity studies of the WHO-composite international diagnostic interview (CIDI): a critical review. J Psychiatr Res. 1994;28:57-84.

28. Wittchen H-U, Pfister H. DIA-X-Interviews: Manual für Screening-Verfahren und Interview. Frankfurt: Swets und Zeitlinger; 1997.

29. American Psychiatric Association. Diagnostic and statistical manual of mental disorders, fourth edition, text revision (DSM-IV-TR). Washington, DC: American Psychiatric Association; 2000.

30. Jacobi F, Höfler M, Siegert J, Mack S, Gerschler A, Scholl L, Busch MA, Hapke $U$, Maske U, Seiffert I, et al. Twelve-month prevalence, comorbidity and correlates of mental disorders in Germany: the mental health module of the German health interview and examination survey for adults (DEGS1-MH). Int J Methods Psychiatr Res. 2014;23:304-19.

31. Jacobi F, Höfler M, Strehle J, Mack S, Gerschler A, Scholl L, Busch MA, Hapke $U$, Maske U, Seiffert I, et al. Twelve-months prevalence of mental disorders in the German health interview and examination survey for adults - mental health module (DEGS1-MH): a methodological addendum and correction. Int J Methods Psychiatr Res. 2015;24:305-13.

32. Jacobi F, Wittchen HU, Holting C, Hofler M, Pfister H, Muller N, Lieb R. Prevalence, co-morbidity and correlates of mental disorders in the general population: results from the German health interview and examination survey (GHS). Psychol Med. 2004;34:597-611.

33. Maske UE, Hapke U, Riedel-Heller SG, Busch MA, Kessler RC. Respondents' report of a clinician-diagnosed depression in health surveys: comparison with DSM-IV mental disorders in the general adult population in Germany. BMC Psychiatry. 2017;17:39.

34. Lampert T, Kroll LE, von der Lippe E, Muters S, Stolzenberg H. Measurement of socioeconomic status in the German health interview and examination survey for adults (DEGS1). Bundesgesundheitsbl. 2013;56:814-21.

35. Bullinger M, Kirchberger I. SF-36 Fragebogen zum Gesundheitszustand. Göttingen: Hogrefe; 1998. 
36. Ware JE Jr, Sherbourne CD. The MOS 36-item short-form health survey (SF36). I. Conceptual framework and item selection. Med Care. 1992;30:473-83.

37. Ellert U, Kurth BM. Health related quality of life in adults in Germany: results of the German health interview and examination survey for adults (DEGS1). Bundesgesundheitsbl. 2013;56:643-9.

38. Ware JE Jr. SF-36 health survey update. Spine. 2000;25:3130-9.

39. Maske U, Buttery A, Beesdo-Baum K, Riedel-Heller S, Hapke U, Busch M. Prevalence and correlates of DSM-IV-TR major depressive disorder, selfreported diagnosed depression and current depressive symptoms among adults in Germany. J Affect Disord. 2016;190:167-77.

40. Jacobi F, Klose M, Wittchen H-U. Mental disorders in the community: healthcare utilization and disability days. Bundesgesundheitsbl. 2004;47: 736-44.

41. Eaton WW, Kalaydjian A, Scharfstein DO, Mezuk B, Ding Y. Prevalence and incidence of depressive disorder: the Baltimore ECA follow-up, 1981-2004. Acta Psychiatr Scand. 2007;116:182-8.

42. Compton WM, Conway KP, Stinson FS, Grant BF. Changes in the prevalence of major depression and comorbid substance use disorders in the United States between 1991-1992 and 2001-2002. Am J Psychiatry. 2006:163: 2141-7.

43. Murphy JM, Laird NM, Monson RR, Sobol AM, Leighton AH. Incidence of depression in the Stirling County study: historical and comparative perspectives. Psychol Med. 2000;30:505-14.

44. Patten SB, Williams JV, Lavorato DH, Bulloch AG, Wiens $K$, Wang J. Why is major depression prevalence not changing? J Affect Disord. 2016;190:93-7.

45. WHO International Consortium in Psychiatric Epidemiology. Cross-national comparisons of the prevalences and correlates of mental disorders. Bull World Health Organ. 2000;78:413-26.

46. Kessler RC, Angermeyer M, Anthony JC, De Graaf R, Demyttenaere K, Gasquet I, De Girolamo G, Gluzman S, Gureje O, Haro JM, et al. Lifetime prevalence and age-of-onset distributions of mental disorders in the World Health Organization's world mental health survey initiative. World Psychiatry. 2007;6:168-76.

47. Patten SB, Williams JV, Lavorato DH, Fiest KM, Bulloch AG, Wang J. Changing perceptions of mental health in Canada. Can J Psychiatr. 2014;59: 591-6.

48. Jorm AF, Reavley NJ. Changes in psychological distress in Australian adults between 1995 and 2011. Aust N Z J Psychiatry. 2012:46:352-6.

49. Kessler RC, Berglund P, Demler O, Jin R, Merikangas KR, Walters EE. Lifetime prevalence and age-of-onset distributions of dsm-iv disorders in the national comorbidity survey replication. Arch Gen Psychiatry. 2005;62: 593-602.

50. Bundespsychotherapeutenkammer. BPtK-Studie zur Arbeits-und Erwerbsunfähigkeit: Psychische Erkrankungen und gesundheitsbedingte Frühverrentung. Berlin: BPtK - Bundespsychotherapeutenkammer; 2013.

51. Bristow K, Patten S. Treatment-seeking rates and associated mediating factors among individuals with depression. Can J Psychiatr. 2002;47:660-5.

52. Brandstetter S, Dodoo-Schittko F, Speerforck S, Apfelbacher C, Grabe H-J, Jacobi F, Hapke U, Schomerus G, Baumeister S. Trends in non-help-seeking for mental disorders in Germany between 1997-1999 and 2009-2012: a repeated cross-sectional study. Soc Psychiatry Psychiatr Epidemiol. 2017: 1005-13.

53. Mojtabai R. National trends in mental health disability, 1997-2009. Am J Public Health. 2011;101:2156-63.

54. Schomerus G, Schwahn C, Holzinger A, Corrigan PW, Grabe HJ, Carta MG, Angermeyer MC. Evolution of public attitudes about mental illness: a systematic review and meta-analysis. Acta Psychiatr Scand. 2012;125:440-52.

55. Angermeyer MC, van der Auwera S, Carta MG, Schomerus G. Public attitudes towards psychiatry and psychiatric treatment at the beginning of the 21st century: a systematic review and meta-analysis of population surveys. World Psychiatry. 2017;16:50-61

56. Mojtabai R, Jorm AF. Trends in psychological distress, depressive episodes and mental health treatment-seeking in the United States: 2001-2012. J Affect Disord. 2015:174:556-61.

57. Mojtabai R. Americans' attitudes toward mental health treatment seeking: 1990-2003. Psychiatr Serv. 2007;58:642-51.

58. Corrigan P. How stigma interferes with mental health care. Am Psychol. 2004;59:614-25.

59. Hybels CF, Landerman LR, Blazer DG. Age differences in symptom expression in patients with major depression. Int J Geriatr Psychiatry. 2012; 27:601-11.
60. Wuthrich VM, Johnco CJ, Wetherell JL. Differences in anxiety and depression symptoms: comparison between older and younger clinical samples. Int Psychogeriatr. 2015;27:1523-32.

61. Wang K, Lu H, Cheung EF, Neumann DL, Shum DH, Chan RC. "Female preponderance" of depression in non-clinical populations: a meta-analytic study. Front Psychol. 2016;7:1398.

62. Bramesfeld A, Grobe T, Schwartz F. Who is diagnosed as suffering from depression in the German statutory health care system? An analysis of health insurance data. Eur J Epidemiol. 2007;22:397-403.

63. Karger A. Gender differences in depression. Bundesgesundheitsbl. 2014;57: 1092-8.

64. Kowitz S, Zielasek J, Gaebel W. Mental healthcare in Germany-current situation and perspectives. Dtsch Med Wochenschr. 2014;139:1249-52.

65. Mack S, Jacobi F, Gerschler A, Strehle J, Höfler M, Busch MA, Maske UE, Hapke U, Seiffert I, Gaebel W, et al. Self-reported utilization of mental health services in the adult German population - evidence for unmet needs? Results of the DEGS1-mental health module (DEGS1-MH). Int J Methods Psychiatr Res. 2014;23:289-303.

66. Rommel A, Bretschneider J, Kroll LE, Prütz F, Thom J. The utilization of psychiatric and psychotherapeutic services in Germany - individual determinants and regional differences. J Health Monitor. 2017;2.

67. Jacobi F, Becker M, Bretschneider J, Müllender S, Thom J, Hapke U, Maier W. Provision of outpatient specialist care for mental disorders : minor regional differences in treatment needs, major regional differences in availability. Nervenarzt. 2016;87:1211-21.

68. Höfler M, Wittchen $\mathrm{H}-\mathrm{U}$. Why do primary care doctors diagnose depression when diagnostic criteria are not met? Int J Methods Psychiatr Res. 2000;9: 110-20.

69. Melchior H, Schulz H, Härter M. Faktencheck Gesundheit - Regionale Unterschiede in der Diagnostik und Behandlung von Depressionen. Gütersloh: Bertelsmann Stiftung; 2014.

70. Bramesfeld A, Grobe T, Schwartz F. Who is treated, and how, for depression? Soc Psychiatry Psychiatr Epidemiol. 2007;42:740-6.

71. Gaebel W, Kowitz S, Zielasek J. The DGPPN research project on mental healthcare utilization in Germany: inpatient and outpatient treatment of persons with depression by different disciplines. Eur Arch Psychiatry Clin Neurosci. 2012;262(Suppl 2):S51-5.

72. Trautmann S, Beesdo-Baum K. The treatment of depression in primary care. Dtsch Arztebl Int. 2017;114:721-8.

73. Sundmacher L, Fischbach D, Schuettig W, Naumann C, Augustin U, Faisst C. Which hospitalisations are ambulatory care-sensitive, to what degree, and how could the rates be reduced? Results of a group consensus study in Germany. Health Policy. 2015;119:1415-23.

Ready to submit your research? Choose BMC and benefit from

- fast, convenient online submission

- thorough peer review by experienced researchers in your field

- rapid publication on acceptance

- support for research data, including large and complex data types

- gold Open Access which fosters wider collaboration and increased citations

- maximum visibility for your research: over $100 \mathrm{M}$ website views per year

At $\mathrm{BMC}$, research is always in progress.

Learn more biomedcentral.com/submission 